\title{
Regularities of Cementite Decomposition in Hypereutectoid Steels
}

\author{
Sergey N. Kutepov ${ }^{1 *}$, Andrey V. Malyarov ${ }^{1}$, Igor V. Minaev ${ }^{1}$, and Alexander E. Gvozdev ${ }^{1}$ \\ ${ }^{1}$ Tula State Pedagogical University by Leo Tolstoy, Tula
}

\begin{abstract}
Comprehensive studies have been carried out and the main regularities of cementite decomposition during thermocyclic processing of carbon-based hypereutectoid steels have been established.
\end{abstract}

\section{Introduction}

The main area of application of the U10 alloy is cutters, saws are tools designed for woodworking. In addition, U10 carbon tool steel allows you to make high-quality needle wire, various parts of cold stamping, coil springs and other springy parts, taps and dies, simple gauges, as well as working parts of hand-held locksmith tools: files, scrapers.

\section{Materials and methods}

Investigated steel grade U10 with different initial state. Thermocyclic treatment (TCT) was carried out at a temperature of $200-100{ }^{\circ} \mathrm{C}$. The samples were pre-coated with a protective coating.

\section{Experimental results and discations}

The first sample of steel grade U10 had the original structure of lamellar pearlite and CII (Fig. 1, a). The total number of cycles was 35.

After thirty-five cycles, the structure of steel grade U10 practically did not change lamellar pearlite and CII (Fig. 1, b). We have the same picture in the steel grade U12 under

\footnotetext{
${ }^{*}$ Corresponding autor: lkutepov.sergei@mail.ru
} 
investigation. Only individual dark inclusions were found in pearlite grains.

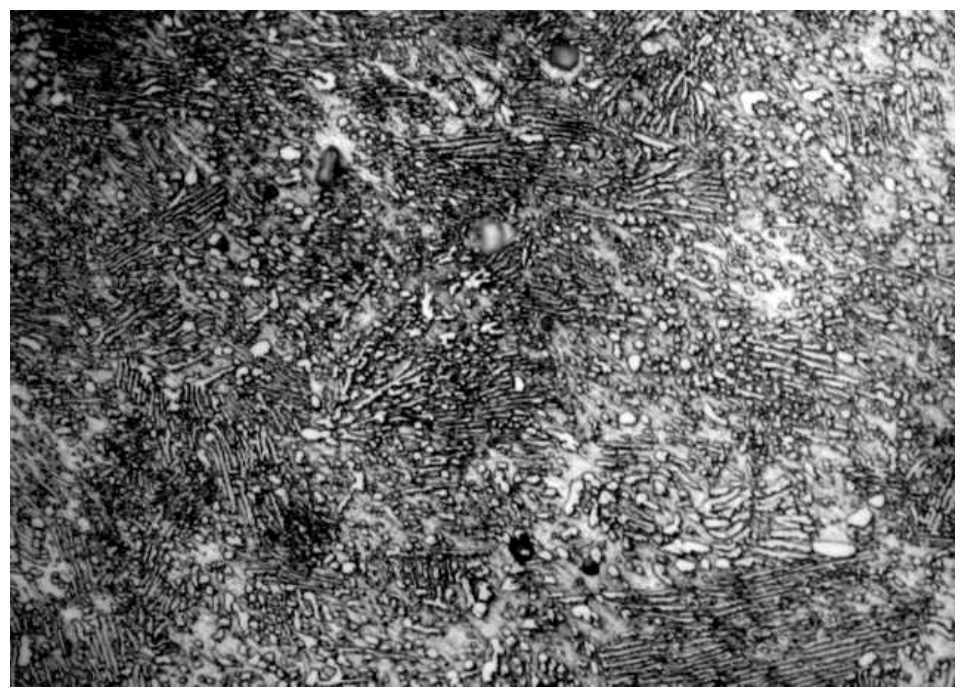

a)

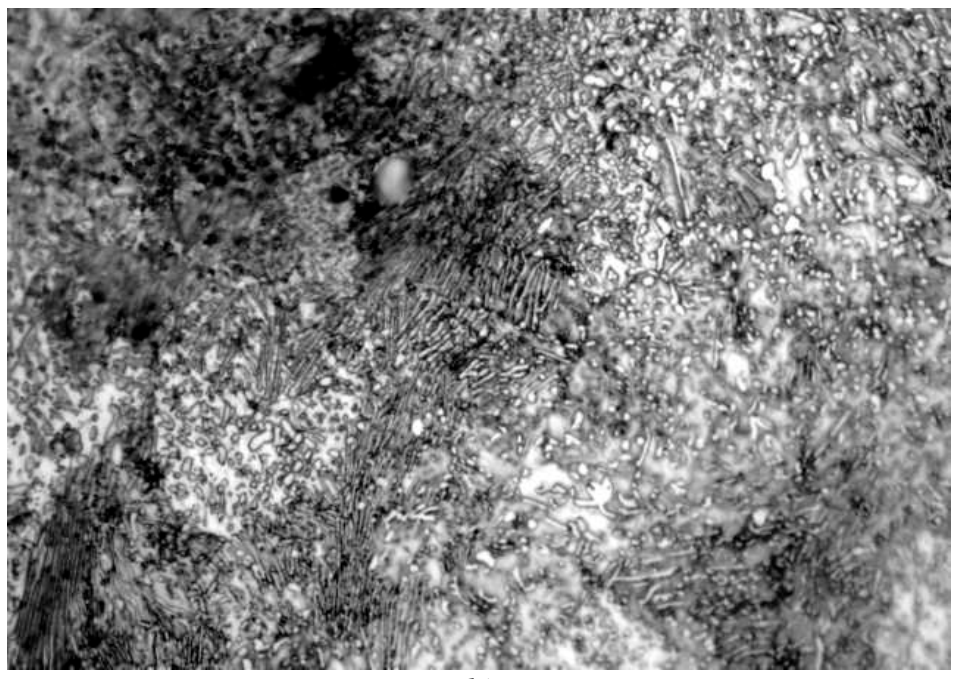

b)

Fig. 1. Microstructure of steel grade U10, $\times 1000$ with the initial state of lamellar pearlite and CII (a) and after 35 cycles (b) 
The second sample of steel grade U10 had the original structure of granular pearlite (Fig. 2, a). The total number of cycles was 35. In this case, the appearance of graphite inclusions was noted (Fig. 2, b). The inclusions are evenly distributed over the surface of the thin section.

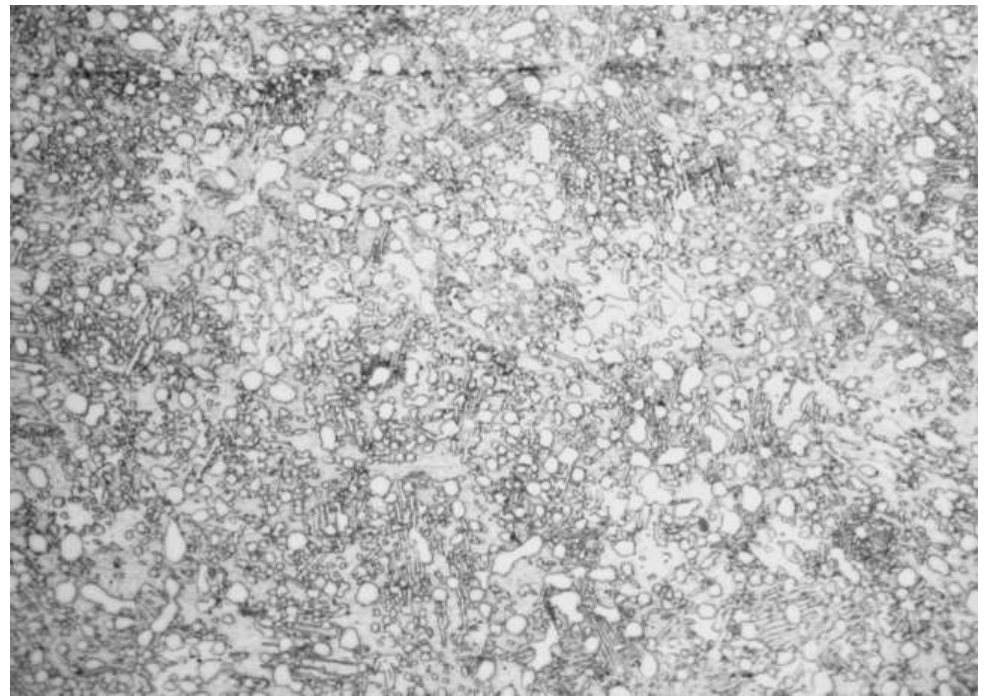

a)

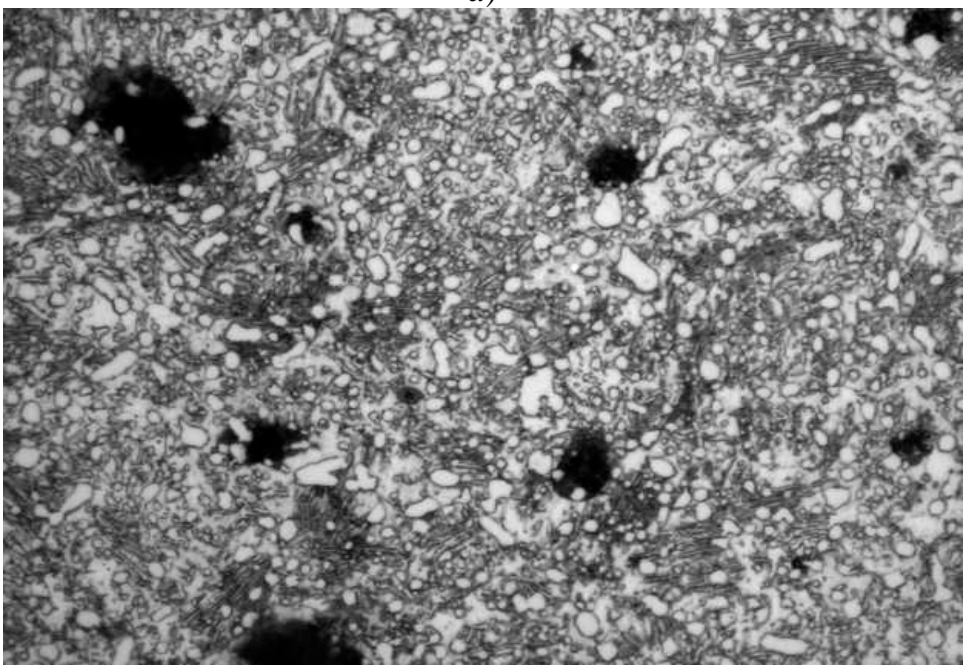

b)

Fig. 2. Microstructure of steel grade U10, $\times 1000$ with the initial state of granular pearlite (a) and after 35 cycles (b) 
Thus, considering steels with different initial states, we can say that the initial state significantly affects the formation of graphite.

Let us combine the TCT results obtained for the entire spectrum of steels with a high carbon content with a granular pearlite structure (Table 1, Fig. 2, b).

Table 1. Parameters of graphite inclusions obtained for various steels in the TCT process

\begin{tabular}{|c|c|c|c|}
\hline Steel grade & Volume fraction of graphite, $\%$ & Average size, $\mu \mathrm{m}$ & Form factor \\
\hline U8A & 0,042 & 3,201 & 0,754 \\
\hline U10 & 0,758 & 7,629 & 0,482 \\
\hline U12 & 0,071 & 5,342 & 0,783 \\
\hline
\end{tabular}

Thus, analyzing the data obtained, we can say that the maximum volume fraction and average size of graphite inclusions are observed in steel grade U10 (Table 1). In contrast to the previously investigated hypereutectoid steels [1], the shape of graphite inclusions is flaky.

So, only structurally free cementite (either $\mathrm{C}_{\mathrm{III}}$ in hypoeutectoid steels, or present in the form of granular pearlite in steels with a high carbon content) is capable of decomposition. As in the previously considered cases, the appearance of graphite leads to a drop in the density of the sample (Fig. 3).

Further, the calculations of the volume fraction of graphite for all steel grades were performed:

for steel grade U8A

$\mathrm{V}_{\mathrm{gr}}=(7,84-7,75) /(7,84-2,65)=0,017=1,7 \%$ (by volume);

for steel grade U10

$\mathrm{V}_{\mathrm{gr}}=(7,56-7,41) /(7,56-2,65)=0,0305=3,0 \%$ (by volume);

for steel grade U12

$\mathrm{V}_{\mathrm{gr}}=(7,73-7,72) /(7,73-2,65)=0,014=1,54 \%$ (by volume) . 


\section{$\rho, \mathrm{r} / \mathrm{cm} 3$}

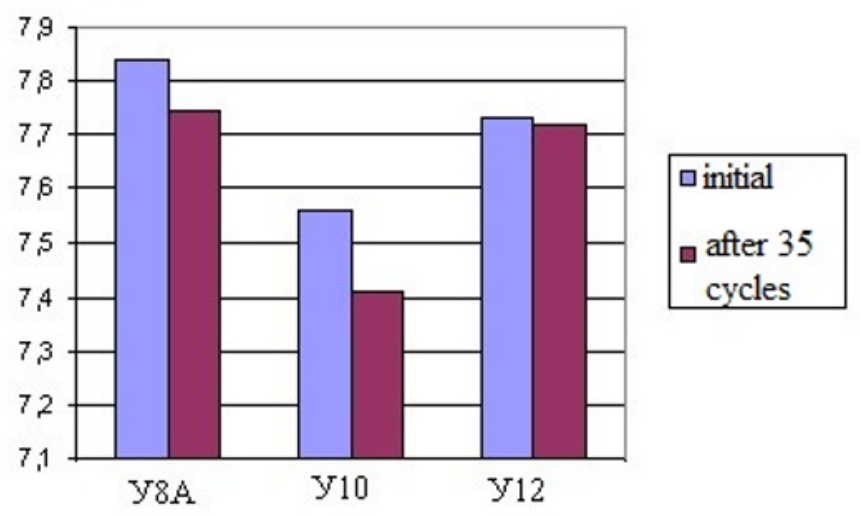

Fig. 3. Change in density in hypereutectoid steels U8A, U10, U12

It can be seen from the results obtained that the discrepancy between the data of microscopic analysis and the results of determining the volume fraction of graphite by decreasing the density is due to the specificity of the methods used.

\section{Conclusion}

It has been established that in the structure of U10 steel with the initial state of granular pearlite, the maximum volume fraction (about $0.8 \%$ ) of graphite is observed during thermal cycling near A0 of cementite. At the same time, the greatest effect of the density drop (by $1.85 \%$ ) of the samples undergoing TCT was noted as compared to the initial state.

The results obtained can be used to create resource-saving processes and technologies for processing structural and tool materials using new nanocomposite lubricants and coatings in various conditions and states of metal systems, taking into account the recommendations of [2-20].

\section{References}

1. A.V. Malyarov, A.E. Gvozdev, I.V. Minaev, I. V. Tikhonov. Structural and phase transformations of carbon steels in different conditions and states: monograph: 2nd ed., Rev. and add. Tula: Publishing house of TulSU, 2020. 278 p. 
2. O.V. Kuzovleva, I.V. Tikhonova, N.E. Starikov, A.E. Gvozdev. The disintegration of cementite of carbon steels during thermal cycling. Proizvodstvo prokat. 2008. No. 8. S. 36-37.

3. I.V. Tikhonova, A.V. Malyarov, A.E. Gvozdev, N.E. Starikov. Influence of the temperature range of thermal cycling treatment on the decomposition of cementite in carbon steels. Procurement production in mechanical engineering. 2010. No. 10. S. 39-41.

4. A. E. Gvozdev, A. G. Kolmakov, A. V. Malyarov, N. N. Sergeev, I. V. Tikhonova. Heterogeneous nucleation of graphite in carbon steels during the decomposition of cementite in the process of TCT near the point A0. Materials Science ... 2013. No. 10. S. 48-52.

5. A.E. Gvozdev, A.G. Kolmakov, A.V. Malyarov, N.N. Sergeev, I.V. Tikhonova. Influence of elements of graphitizers on the decomposition of cementite during thermal cycling near A0 carbon steels. Materials Science. 2013. No. 11. S. 43-45.

6. A.E. Gvozdev, A.G. Kolmakov, A.V. Malyarov, N.N. Sergeev, I.V. Tikhonova, M.E. Prutskov. Conditions for the manifestation of cementite instability during thermal cycling of carbon steels. Materials Science. 2014. No. 10. S. 31-36.

7. Nawaz W., Xu S., Huang B., Wu X., Wu Z., Li Y., "Nanotechnology and immunoengineering: how nanotechnology can boost car-t therapy“, Acta Biomaterialia. 2020. No. 109. pp. 21-36.

8. Povarova K.B. Powder Metallurgy of Tungsten Alloys, Proceedings of 3rd EURO PM 2004 Powder Metallurgy World Congress and Exhibition, 2004, No. 5, pp. 106-112.

9. Antsiferova I.V., Esaulova I.A., "Nanotechnology research and education centers as an intellectual basis of nanotechnology in Russia“,Middle East Journal of Scientific Research. 2013. No. 13. pp. 127-131.

10. Wong K.K.Y., Liu X., "Nanotechnology meets regenerative medicine: a new frontier?“, Nanotechnology Reviews. 2013. T. 2. No. 1. pp. 59-71.

11. Balykina A.M., Rybalko V.V., Shelamov V.A., "Practical tasks of training of specialists for nanotechnology industry“,International Journal of Nanotechnology. 2019. T. 16. No.6-10. pp. 562-568.

12. Occhiutto M.L., Costa V.P., Maranhão R.C., Konstas A.G., "Nanotechnology for medical and surgical glaucoma therapy-a review, Advances in Therapy. 2020. T. 37. No.1. pp. 155-199.

13. Phung C.D., Pham L.M., Jeong J.-H., Yong C.S., Kim J.O., Tran T.H., Nguyen H.T., "Current developments in nanotechnology for improved cancer treatment, focusing on tumor hypoxia“, Journal of Controlled Release. 2020. T. 324. pp. 413-429.

14. Dar A.H., Rashid N., Dar M.A., Majid I., Hussain S., "Nanotechnology interventions in aquaculture and seafood preservation", Critical Reviews in Food Science and Nutrition“, 2020. T. 60. No. 11. pp. 1912-1921. 
15. Desai P., Thumma N.J., Wagh P.R., Zhan S., Wang J., Prabhu S., Ann D., "Cancer chemoprevention using nanotechnology-based approaches“,Frontiers in Pharmacology. 2020. T. 11. pp. 323.

16. Choubdar N., Avizheh S., "Nanotechnology based delivery systems of drugs currently used to treat alzheimer's disease“,Nanoscience and Nanotechnology - Asia. 2020. T. 10. No. 3. pp. 228-247.

17. Khorev,A.I., "Alloying and heat treatment of structural $(\alpha+\beta)$ titanium alloys of high and superhigh strength“, Russian Engineering Research, 2010, vol. 30, No. 7, pp. 682688.

18. E.V. Ageev, R.A. Latypov, Fabrication and investigation of carbide billets from powders prepared by electroerosive dispersion of tungsten-containing wastes, Russian Journal of Non-Ferrous Metals, 2014, vol. 55, No. 6, pp. 577-580.

19. E.V. Ageeva, E.V. Ageev, N.M. Horyakova, Morphology of copper powder produced by electrospark dispersion from waste, Russian Engineering Research, 2014, vol. 34, No. 11, pp. 694-696.

20. E.V. Ageev, R.A. Latypov, E.V. Ageeva, Investigation into the properties of electroerosive powders and hard alloy fabricated from them by isostatic pressing and sintering, Russian Journal of Non-Ferrous Metals, 2015, vol. 56, No. 1, pp. 52-62. 